\title{
Metas do design pedagógico: um olhar na construção de materiais educacio- nais digitais
}

\author{
Patricia Alejandra Behar \\ Universidade Federal do Rio Grande do Sul (UFRGS) \\ Caixa Postal 5071 - 90.041-970 - Porto Alegre - RS - \\ Brasil \\ pbehar@terra.com.br
}

\author{
Cristina Alba Wildt Torrezzan \\ Universidade Federal do Rio Grande do Sul (UFRGS) \\ Caixa Postal 5071 - 90.041-970 - Porto Alegre - RS - \\ Brasil \\ crisawt@gmail.com
}

Resumo Frente a expansão da internet e das tecnologias digitais em várias áreas da sociedade atual, verifica-se a crescente aplicação de recursos digitais na educação. Porém, a maioria desses materiais educacionais digitais (MED's) é desenvolvida a partir da simples digitalização de materiais educacionais analógicos, normalmente ocorrendo um desequilíbrio entre fatores técnicos, gráficos e pedagógicos. Portanto, torna-se necessário a construção de novas práticas pedagógicas que se relacionem harmonicamente com esses novos recursos e, principalmente, que sejam centradas na aprendizagem do aluno. A partir disso, esta pesquisa investiga a construção de materiais educacionais digitais sob o ponto de vista do design pedagógico (DP). Primeiramente, este artigo organiza e relaciona as metas do design pedagógico. Após, relata o processo de aplicação e validação dessas metas, através da construção e aplicação do OA PEDESIGN. Por fim, aborda a aplicação das referidas metas na elaboração da tabela de parâmetros para a construção de materiais educacionais digitais baseadas no DP. O objetivo é gerar uma reflexão sobre a importância da aplicação do design pedagógico em materiais educacionais digitais, assim como investigar os parâmetros responsáveis pela elaboração de MED’s que possibilitem a ação crítica do aluno sobre o objeto de estudo.

Palavras-Chave: Educação a distância, materiais educacionais digitais, design de interface, relação homem-máquina, design pedagógico, aprendizagem.

\begin{abstract}
Due to the expansion of the internet and digital technologies in several areas of today's society, an increase in the application of digital resources in Education has been verified. However, most of these digital educational materials (DEM) are developed from the simple digitalization of analogic educational materials, usually occurring an unbalance among technical, graphic and pedagogic factors. Therefore, it is necessary to develop new pedagogic practices which harmonically relate to these new resources, and that they are centered in student's learning process. Aiming at such goal, this research investigates the development of digital educational materials from pedagogic design (PD) perspective.. At first, this article organizes and related pedagogic design objectives. Then, it narrates the process of application and validation of these objectives, through the development and application of OA PEDESIGN. At last, it approaches the application of the referred goals to the development of a table of parameters for the creation of pedagogic-design-based digital educational materials. The objective is to promote a reflection on the importance of pedagogic design application in digital educational materials, as well as to investigate the parameters of DEM development which may allow student's critic action over the study object.
\end{abstract}

Keywords: Distance education, digital educational materials, interface design, human-computer relationship, pedagogic design, learning process. 


\section{Introdução}

O design pedagógico (DP), elaborado por esta pesquisa, integra fatores técnicos, gráficos e pedagógicos durante a elaboração de materiais educacionais digitais. Objetiva, desse modo, colaborar na construção de materiais educacionais digitais que possibilitem ao usuário uma aprendizagem autônoma, crítica, divertida, surpreendente e construtivista. O material educacional digital (MED), por sua vez, é todo o material educacional que aplica algum tipo de tecnologia digital na sua elaboração. No entanto, verifica-se que a simples união harmônica de tecnologias digitais a materiais educacionais não é responsável pela contemplação de um design pedagógico. Ele dependerá do planejamento técnico-gráficopedagógico a ser realizado por uma equipe interdisciplinar. Através do equilíbrio entre esses fatores será possível construir um MED que contemple as necessidades do novo perfil do aluno da geração digital: participação ativa, interatividade com diferentes fontes de informações, interações, trabalho colaborativo, criação de estratégias, exploração não-linear, resolução de desafios.

A partir da teoria construtivista de Piaget [15] justifica-se a necessidade do material educacional digital possibilitar que o aluno realize diferentes relações através da interação com colegas e professores, assim como da interatividade com o conteúdo e diferentes fontes de informação. Segundo Ugulino et AL [29], o trabalho colaborativo, quando realizado com o apoio de ferramentas computacionais, sofre influência das limitações desse meio. Portanto, no caso do conteúdo ser apenas apresentado ao aluno, sem que ele possa atuar com um pensamento crítico, reflexivo e relacional, a aprendizagem será apenas mecânica. As novas informações serão aprendidas sem que ocorra a interatividade com conceitos relevantes existentes na estrutura cognitiva desse aluno. Com isso, o novo conteúdo passará a ser armazenado isoladamente ou por meio de associações arbitrárias na sua estrutura cognitiva [4].

Para que o design pedagógico efetivamente possibilite ao aluno a construção do conhecimento é preciso que ele propicie um ambiente motivador onde o aluno encontre espaço para atuar com uma postura crítica, criativa, investigativa e autônoma. Essas características serão contempladas no momento em que a metodologia utilizada estiver centrada no aluno e na sua ação sobre o MED. As interfaces devem estar contextualizadas na sua cultura, tanto em relação a aspectos gráficos e ergonômicos, quanto a respeito da lógica aplicada à organização do conteúdo e da estrutura interativa. O aluno deve ter a oportunidade de percorrer livremente o material educacional digital de uma maneira não-linear, ou seja, conforme a lógica que estiver construindo em cada momento de acesso. Além disso, ele deve entrar em contato com situações aleatórias que lhe causem instigações e que necessitem ser investigadas a partir da interação com colegas, materiais didáticos (utilização de várias mídias) e da relação dessas com as informações e conceitos prédefinidos pelo referido aluno. A trajetória dessa busca deve ser criada pelo próprio usuário, por isso a necessidade de uma navegação não-linear e que não conduza a uma lógica específica.

O usuário, ao entrar em contato com o material educacional digital, necessita apropriar-se das informações, de modo a agir a partir delas e não segundo elas. Precisa ser sujeito do seu próprio aprendizado. Essa concepção educacional fundamentada no pensamento de Piaget muitas vezes é mal interpretada por educadores. Não significa que o aluno deva "aprender sozinho”, mas sim encontrar liberdade para que ele, a partir da interatividade com o material disponibilizado e da interação com colegas e professor, construa as suas próprias conclusões. Ao professor cabe propiciar aos alunos essas situações em que eles irão entrar em contato com o(s) objeto(s), interagir, contra-argumentar, desequilibrar-se, assimilar, reequilibrar-se, construir. Verifica-se, dessa forma, a importância em haver um diálogo entre o conteúdo abordado no material educacional digital e o pensamento do aluno, que será apoiado pelo equilíbrio entre os fatores técnicos, gráficos e pedagógicos, ou seja, pelo design pedagógico.

A partir dessas relações é possível verificar a influência do design de interface no planejamento da interatividade de materiais educacionais digitais. Ocorre que, algumas vezes, o design é interpretado como um simples ilustrador, com a função de propiciar um fino acabamento ao trabalho. Porém, ele abrange uma conceituação mais profunda, relacionada com a estrutura do material, não devendo ser visto como uma superficial cobertura, mas como parte integrante do objeto construído. Segundo Gomes [11], essa pode ser uma das causas de alguns MED's não corresponderem às expectativas dos profissionais de ensino. Segundo o referido autor, torna-se necessário que o design de interface considere aspectos do processo de aprendizagem. Portanto, assim como o arquiteto pensa a fachada na medida em que projeta a planta técnica, a equipe desenvolvedora de material educacional digital necessita pensar no design de interface ao mesmo tempo em que planeja o conteúdo, a tecnologia e a programação. Desse modo, este artigo aborda as metas do design pedagógico, elaboradas e validadas por esta pesquisa com o intuito de apoiar a construção de materiais educacionais digitais de qualidade. Além disso, objetiva-se através delas, colaborar com a formação de profissionais da área de design, informática e educação. Inicialmente, as metas do design pedagógico serão con- 
ceituadas e relacionadas entre si e com a construção de MED's. Após, será relatado o processo de aplicação dessas metas através da construção e avaliação do objeto de aprendizagem PEDESIGN. Por fim, as referidas metas serão organizadas numa tabela de parâmetros para a construção de materiais educacionais digitais baseados no design pedagógico. Com um caráter reutilizável, o intuito é, através dessa tabela, apoiar a construção de MED’s que possibilitem a ação crítica do aluno sobre o objeto de estudo.

\section{Conceituando o Design Pedagógico}

Algumas nomenclaturas foram utilizadas ao longo dos anos por pesquisas envolvendo o design voltado á educação. Entre elas, podem ser destacadas o Design instrucional [21] design didático [3], design educacional [21] e design de sistemas [25] são as mais conhecidas.

O design instrucional é conceituado por Paloff e Pratt [21] como "uma metodologia de planejamento educacional amplamente utilizada nos EUA e em alguns países da Europa. Serve para planejar cursos e materiais didáticos em diferentes mídias, bem como currículos e sistemas educacionais". Envolve as áreas de ciências humanas, ciência da administração e ciência da informação. Amaral et al [3] reporta o design didático ao design instrucional, conceituando-o como designador do "processo de análise de requisitos, planejamento e especificação para a elaboração de cursos, disciplina ou uma aula." Já o design educacional segundo [20] é o processo de conceber e desenvolver ambientes para otimizar a aprendizagem de determinadas informações em determinados contextos. O Design de Sistemas é "a capacidade técnica de planejamento de novos sistemas, ou re-planejamento de sistemas existentes, qualquer que seja seu grau de complexidade" [25]. A partir dessas conceituações Verifica-se que esses tipos de design atuam em áreas singulares, contemplando a área da educação ou a área da informática. Porém, apenas um planejamento pedagógico ou técnico não se mostra suficiente para a construção de MED's, já que essas questões norteadoras envolvem o concomitante planejamento técnico, gráfico e pedagógico. Desse modo, esta pesquisa propõe a elaboração do design pedagógico (DP), conceituando-o como aquele que une várias áreas de estudo (informática, design e educação) e integra elementos relacionados a práticas pedagógicas, ergonomia, programação informática e composição gráfica. O seu objetivo é colaborar na construção de materiais educacionais digitais que possibilitem ao usuário uma aprendizagem autônoma, crítica, divertida, surpreendente e significativa.

A escolha do termo design pedagógico justifica-se na intenção do próprio nome explicitar a união de diferentes fatores. Portanto, $\mathrm{DP}=$ design+pedagogia, ou seja, refere- se a integração entre o planejamento pedagógico, programação informática e desenho de interface. Para a contemplação do equilíbrio entre os fatores técnicos, gráficos e pedagógicos em MED’s, o design pedagógico ressalta ainda a importância de uma equipe interdisciplinar, caso contrário um desses fatores poderá acabar prevalecendo sobre o outro. esta pesquisa ressalta ainda a diferença entre a nova proposta do design pedagógico e o design instrucional. Considera-se que eles não sejam sinônimos. Na realidade entende-se que o design instrucional seja uma das competências do design pedagógico. Para melhor entendimento torna-se relevante citar [25]: “(...) não há muita literatura original sobre o design instrucional de objetos de aprendizagem. (...) o que falta é uma bibliografia paralela sobre outras fases de planejamento e gestão de grandes projetos de inovação educacional”.

Portanto o design pedagógico atua na proposição de um novo planejamento de MED's, por sua vez baseado numa metodologia que ultrapassa os limites da educação tradicional. Relaciona-se com a administração de distintas áreas de estudo. Por isso o design pedagógico pode ser ainda definido como a união dos tipos de design instrucional, educacional, didático e de sistema. Ele não somente elabora interfaces interativas como organiza e relaciona diferentes mídias com conteúdos, práticas pedagógicas, o sistema informático utilizado e a aprendizagem do aluno. $\mathrm{O}$ estado da arte do design pedagógico está justamente na gestão dessas áreas de estudo durante a fase de planejamento, na tentativa de construir um material educacional digital que possibilite ao usuário uma postura autônoma, motivadora, crítica, divertida, interativa, desafiadora, instigante, impressionante e colaborativa. Enquanto os tipos de design citados possuem como foco o produto a ser gerado, o DP foca a ação do usuário sobre o produto. A intenção é contribuir para a discussão sobre o desenvolvimento de MED's que apóiem a aplicação das tecnologias digitais na educação e colaborem para a elaboração de uma nova concepção de ensino para além dos limites da educação tradicional.

\section{Metas do design pedagógico}

A partir do cruzamento da pesquisa bibliográfica realizada por este estudo a respeito dos principais elementos envolvidos na construção de materiais digitais em geral; com os principais elementos do design pedagógico (fatores técnicos, gráficos e pedagógicos) e objetivos educacionais; esta pesquisa elaborou as metas do design pedagógico, ou seja, pontos a serem contemplados durante o concomitante planejamento técnico-gráfico-pedagógico de MED’s. Eles são abordados a seguir. 


\subsection{A utilização da imagem sob o ponto de vista do design pedagógico}

Normalmente um material educacional digital tornase bem mais atraente quando possui imagens e ilustrações gráficas. Porém, reportar a elas um caráter meramente ilustrativo e instrucional significa desperdiçar o seu potencial pedagógico. É preciso entender como o sujeito interage com a imagem, para então possibilitar a sua ação sobre elas e o desenvolvimento de habilidades icônicas.

Este trabalho define a imagem como um dos tipos de linguagem capaz de propiciar a relação do sujeito com o meio em que vive. Identificou-se a necessidade de definila em 2 instâncias: Imagem mental - atua como a interiorização do real ou ainda a interpretação do real pelo eu (atividade psíquica); Imagem Física - seja ela visual, acústica, tátil ou olfativa, reporta às imagens mentais de modo ao sujeito criar esquemas e realizar assimilações.

Segundo Silveira [28] o que ocorre na realidade é que o significado para a compreensão é construído essencialmente através de pistas contextuais nas quais a imagem é processada. Porém, como ressalta a autora, nem sempre a interpretação do sujeito poderá condizer com a intenção do autor, já que a interpretação de uma imagem é baseada nas experiências do sujeito que a interpreta, referenciadas, por sua vez, na sociedade em que vive e na sua habilidade cognitiva. É como relata Canetti [6]: somente se torna real aquilo que reconhecemos quando, antes disso, o experimentamos.

Trata-se da relação sujeito/objeto/contexto. É nesse momento que ocorre a interação entre esses elementos [1]. A partir dessa relação que o sujeito é capaz de refletir e construir conhecimento. Porém, é preciso que as imagens sejam utilizadas no âmbito da representação evitando o da simples apresentação.

Segundo Max Bense [5] objetos apresentados funcionam ontologicamente, objetos representados funcionam semioticamente. Logo, ao considerar uma imagem como um elemento que apresenta uma informação ou conceito está se aproximando da teoria da Gestalt, que acredita que a imagem comunica por si mesma (por insight). Se isso realmente ocorresse vários sujeitos ao interpretar uma obra de arte abstrata teriam a mesma compreensão. Todas as pessoas ao "brincar" com a forma das nuvens visualizariam as mesmas imagens. No entanto isso não acontece, pois o processo de interpretação de uma imagem é bem mais complexo. Segundo a teoria de Piaget, o sujeito "retira" da imagem aquilo que lá ele coloca através da abstração reflexionante (seja ela pseudo-empírica ou refletida) [4], ou seja, a interpretação será o resultado daquilo que o sujeito transferir à imagem a partir do seu conhecimento. Portanto, torna-se importante que o material educacional digital contemple um design pedagógico que propicie a ação do sujeito sobre a imagem, pois somente através dessa relação que a imagem poderá apoiar o seu processo de aprendizagem.

A relação entre a imagem e a cognição do usuário pode ser melhor compreendida a partir do conceito da relevância. Segundo Silveira [28] esse conceito possui uma base cognitiva, numa perspectiva graduada e comparativa, estabelecendo uma relação de equilíbrio entre o custo mental despendido e os efeitos contextuais alcançados ao ser processada uma informação.

Para conquistar tal objetivo é necessário inserir os signos num contexto compatível com o aluno (sujeito) porque propiciará um equilíbrio entre o esforço mental e o efeito obtido (construído) pelo sujeito, disponibilizando um nível de representações mentais durante o processo interpretativo. Desse modo, será possibilitada uma interpretação sensório-motora ou linguística a respeito do conteúdo do material educacional digital.

Isso indica que, o usuário ao interagir com os signos de um material educacional digital irá relacionar essa nova informação com a já existente e no mínimo armazená-la na sua memória. Caso ela ainda cause uma reequilibração nos conceitos pré-estabelecidos desse sujeito, gerando a construção de novos conceitos, essa interação será considerada satisfatória e receberá o nome de implicação contextual [28].

Segundo [28] a partir da uma relação de equilíbrio entre o esforço mental e o resultado alcançado, os efeitos contextuais podem ser caracterizados em 3 tipos: implicação contextual - derivando uma nova suposição, fortalecimento - ampliando ou fortalecendo a suposição preexistente e contradição - que elimina uma das duas suposição contraditórias. A partir dessas relações é possível entender como o usuário interage com a imagem. É preciso aplicá-la num contexto e num nível de representações mentais que se tornem disponíveis durante o processo interpretativo, visando equilibrar a relação entre o esforço mental e o efeito a ser obtido. Esse equilíbrio relaciona-se com a ergonomia do MED, principalmente no que se refere à utilização dos ícones das interfaces, tema que será abordado na seção a seguir, devido a sua importância e complexidade. Porém, desde já se verifica a importância de não subestimar a ação do sujeito sobre a imagem. Utilizá-la como mero artifício ilustrativo seria o mesmo que desperdiçar a habilidade cognitiva do sujeito. Portanto, ao elaborar um material educacional digital é necessário que os elementos de composição sejam planejados de forma a instigar um olhar inteligente, ou seja, de modo a avaliar cada impressão da imagem considerando a si próprio como ser complexo [1]. 


\subsection{Aplicação do caráter icônico da imagem na ergonomia do MED}

Primeiramente, torna-se necessário uma reflexão sobre as metas do design pedagógico e as teorias semióticas. A semiótica peirceana volta-se ao estudo do signo, enquanto a semiótica greimasiana detém-se nas relações através desse signo. Sob o ponto de vista do design pedagógico, esta pesquisa compreende que a interação sujeito-objeto de Piaget [15] relaciona-se à relação entre o plano de expressão e o plano do conteúdo estudado por Greimas [12]. Por outro lado, identifica uma proximidade entre a função dos ícones de interface e as classificações de Peirce, já que a relação entre o usuário e os ícones de interface deve ser mais intuitiva e nem tanto construtivista (referindo-se estritamente a questões ergonômicas). Portanto, o design pedagógico abordará a semiótica peirceana nesta meta, referindo-se à relação usuário-ícone das interfaces e adotará a semiótica greimasiana no planejamento da relação usuário-MED através da experiência estética, estudada na sequência.

Segundo Santaella e Nöth [27] no momento em que a imagem é entendida como semelhança e similaridade de signos retratados, têm-se ela pertencente a classe dos ícones. Na relação entre o usuário e o ícone da interface o signo corresponde à forma desse ícone na interface, ao seu desenho; o objeto corresponde a sua funcionalidade e o signo corresponde ao signo gerado na mente do usuário. Portanto, torna-se necessário que o usuário consiga descobrir o objeto do signo quando interagindo com ele. A usabilidade da interface, por sua vez, será diretamente proporcional à rapidez e qualidade dessa leitura e interpretação que terá que ser feita pelo usuário. Essa relação entre o ícone e o usuário é apoiada pela Engenharia semiótica de Souza [9], uma abordagem da interação homem-máquina que objetiva apoiar soluções práticas para o design de interfaces. Relaciona a conquista da usabilidade à ação de considerar a interface como um sistema de comunicação interativo com o usuário e que necessita informar a sua funcionalidade e o próprio sistema de comunicação.

Segundo Ferreira [10] um grande equívoco ocorre quando se reporta os signos da interface apenas à uma classificação indexal. No momento em que o usuário, por exemplo, clica no ícone de uma "folha em branco" na intenção de abrir um novo documento, num determinado editor de texto. Essa ação pode ser reportada à uma classificação indexal, uma vez que o seu acesso acarretará numa ação do sistema (relação causal entre o signo e o objeto). Porém há também um relacionamento importante entre os elementos visuais do signo e a função que desempenha. O usuário somente reporta o desenho de um retângulo branco a uma folha e por sua vez a um novo arquivo devido a uma questão simbólica, uma convenção.
Portanto esse signo também aborda um caráter simbólico, uma vez que num outro contexto ou sociedade pode não ser facilmente identificado se essa relação simbólica não ocorrer.

Essa distinção simbólica que garante a adoção de um significado para o usuário, Leite [17] conceitua como Signo de interface. Segundo o autor os signos de interface (entre eles o ícone) podem desempenhar a função de permitir ao usuário a realização de uma determinada ação - função de acionamento -, mostrar os eventos ou estados do sistema - função de revelação - , ou ainda comunicar uma mensagem ao usuário, através do acionamento e revelação - função de metacomunicação. Essas mensagens icônicas são importantes para que o usuário sinta-se seguro e possa construir uma lógica de utilização das interfaces do MED. É baseado nessa confiança que o usuário terá o controle de suas ações e encontrará liberdade suficiente para criar regras e estratégias de exploração do conteúdo abordado pelo MED.

Um alto grau de iconicidade propicia uma interpretação mais relacionada com signos que facilmente relacionam-se com o usuário. São importantes, por exemplo, quando referentes a ferramentas responsáveis pela navegação de um material digital educacional (figuras que representam o ato de: ir, voltar, sair,...). Ou em momentos mais comunicativos e nem tanto construtivistas onde a imagem conquista um caráter mais representativo e o sujeito facilmente projeta nela o significado de um determinado conceito. Por outro lado a imagem com baixo grau de iconicidade coloca a ação do sujeito numa posição de destaque, pois ele terá que utilizar um número maior de esquemas ou ainda construir novos para assimilar aquela imagem. Esta com certeza gerará maiores desequilíbrios que a primeira, mas por outro lado possuirá uma propensão a possibilitar mais construções de conhecimento.

\subsection{Construção do conhecimento através da experiência estética}

Em meio ao contexto entre o visualizar e o sentir é que Greimas [12] situa a estética, reportando-a a percepção de sensações através de relações recíprocas entre o inteligível e o sensível [12]. Desse modo, entende-se que o objetivo da estética é surpreender o sujeito, para então se fazer notar, seja através do belo ou do feio, do agradável ou do irritante - o importante é possibilitar que o observador construa efeitos de sentido para o objeto em análise.

Nessa concepção Greimasiana, a arte (através da estética) dá forma ao conteúdo para que o seu significado inteligível seja interpretado através dos sentidos [23]. Porém, há várias metodologias de aplicação. Quando é 
utilizada em informações publicitárias, ela objetiva convencer o observador sobre um sentido pré-construído sobre determinado produto. Já no âmbito da educação, não há o objetivo de utilizar a estética para condicionar o sujeito, embora o método tradicional de ensino algumas vezes demonstre o contrário, quando teorias são simplesmente repassados aos alunos através de conteúdos pré-definidos. Isso ocorre porque a educação tradicional costuma enfocar o conhecimento inteligível, causando uma sobreposição desse sobre o saber sensível. Porém, na atual sociedade globalizada e com a expansão cada vez maior do computador e da internet, torna-se muito fácil o acesso a informação. Conteúdos, fórmulas e até bibliografias completas podem ser observadas e reproduzidas na rede. A escola não é mais a única fonte de conhecimento científico e deve aprimorar os seus métodos de ensino para ser capaz não apenas de comunicar uma informação, mas desenvolver a capacidade do pensamento crítico, de modo ao aluno ser capaz de interagir, relacionar e selecionar tantas informações. Para isso é preciso unir o saber sensível ao inteligível, numa relação de equilíbrio entre os dois.

A experiência estética atua como forte aliada a esse objetivo. Segundo a semiótica greimasiana, ela possibilita a transformação da relação sujeito-objeto através da ruptura das ações automatizadas. Permite que o indivíduo construa efeitos de sentido, uma vez que se opõe aos condicionamentos da dessemantizada rotina cotidiana, estabelecendo um "novo estado de coisas" [13].

Através da experiência estética considera-se o aluno como sujeito da construção do conhecimento, de modo a possibilitar que ele elabore um efeito de sentido para o seu objeto de estudo e não simplesmente aceite um determinado conceito. Desse modo, o enunciador (autor) possibilita ao enunciatário (leitor) a construção de um efeito de sentido para um determinado conteúdo, independente dele se assimilar ou não com a do enunciador. A ênfase é dada às regulamentações realizadas ao longo de discussões sobre o referido assunto. É nessa relação de equilíbrio entre o agir e o sentir que a Semiótica Greimasiana atua. Através da aplicação dessa semiótica na educação, portanto, objetiva-se colocar em prática essas relações entre o pensamento crítico e o conteúdo abordado, contemplando a relação sujeito-objeto de Piaget.

A proposta da aplicação da Semiótica Greimasiana na elaboração de materiais educacionais digitais objetiva a contemplação de uma prática pedagógica que considere o pensamento crítico do aluno como parte integrante do conteúdo a ser abordado, assim como a arte contemporânea considera o expectador como parte integrante da sua obra. A essência dessa questão está na relação entre o plano de conteúdo e o plano da expressão.

O plano do conteúdo refere-se ao significado do tex- to, ou seja, o que ele está comunicando e de que maneira. Já o plano de expressão refere-se à manifestação desse conteúdo num sistema de significação verbal (línguas naturais), não-verbal (música, imagem, entre outros) ou sincrético (aquele que une vários tipos de linguagem) [23]. A partir das cinco estéticas propostas por Greimas [13] é possível analisar como o plano da expressão e do conteúdo relacionam-se através da estética e podem possibilitar uma experiência estética ao usuário do MED. Na estética clássica a ação do sujeito prevalece sobre a do objeto (do ponto de vista semiótico), há um deslumbramento pelas formas e luz, na direção da perfeição. Na estética da graça a ação do sujeito já não é tão soberana sobre a do objeto que o fascina, seduz. Na estética da revelação a atividade do objeto sobressai à do sujeito. Relaciona-se ao excesso, o objeto intimida o sujeito por meio do sincretismo visual, olfativo e tátil. Na estética da penetração o objeto atrai ao mesmo tempo em que afasta o sujeito por provocação a partir da decomposição visual da forma, recursos cromáticos e táteis. Já na estética da purificação o objeto absorve o sujeito e ambos se dissolvem. Cabe ressaltar que a relação sujeito-objeto na experiência estética está sendo analisada sob um prisma paralelo ao de Piaget. Nela, tanto o sujeito pode dominar o objeto, como pode ser absorvido por ele. A dominação do sujeito pelo objeto refere-se ao envolvimento, à penetração do usuário no objeto através da experiência estética, como por exemplo ocorre nos jogos de videogame ou no mundo simulado - o usuário penetra ativamente no mundo virtual de modo a, naquele momento, ele se tornar real (nesse sentido que ocorre a dominação do objeto sobre o sujeito). Portanto o domínio do objeto nada tem a ver com a submissão do aluno, pelo contrário. Somente a partir da postura autônoma, ativa e de abstrações que essa relação é construída pelo aluno na experiência estética. Desse modo, a relação semiótica greimasiana integra-se à interação sujeito-objeto de Piaget, pois ambas baseiam-se na ação ativa do sujeito e na sua relação com o objeto.

As experiências estéticas intermediadas pelos meios digitais, incluindo-se os MED's, têm a possibilidade de tornarem-se mais envolventes do que as realizadas através da leitura de um livro ou da visualização de uma obra de arte ou filme. As tecnologias digitais possibilitam que o usuário participe ativamente da experiência, seja um integrante dessa relação, ao contrário de simplesmente assistir o desenrolar de uma estória, a distância. Através dessa atuação, o sujeito tornar-se mais atento e sensível aos acontecimentos do seu entorno, tomando uma melhor consciência deles, conquistando uma maior oportunidade e capacidade de refletir sobre eles. Ocorre uma experiência estética mais intensa.

Porém, a simples aplicação de diferentes mídias e interfaces interativas não são suficientes para a obtenção de uma experiência estética. Torna-se de fundamental impor- 
tância diferenciá-la de uma simples experiência sensorial. A simples sensação, por exemplo, é uma experiência sensorial. É preciso “combinar e articular os dados sensórios simples (luzes, cores, sons) numa configuração que carregue um significado maior do que a mera soma de pequenas experiências sensoriais” [16]. Portanto, a experiência possibilitada pelo material educacional digital será considerada uma experiência sensível no momento em que permitir a realização de relações por parte do sujeito, de modo a denotar um sentido, ou seja, "uma significação que se espraia para além dos estímulos elementares provenientes dos materiais empregados” [16]. Verifica-se, portanto, que a estética torna-se um fator importante na elaboração de materiais educacionais. Ela colabora para a construção de uma abordagem sincrética. Juntamente com a arte, aplica o semi-simbolismo ao conteúdo, com a possibilidade de surpreender o sujeito e, a partir desse estranhamento, instigá-lo a investigar um efeito de sentido para o respectivo objeto de estudo.

\subsection{Proposição de um planejamento técnico de apoio à trajetória do usuário}

Ao elaborar um material educacional digital há a necessidade de adotar-se um sistema. Esse será responsável pelos aspectos técnicos de análise e programação, relacionados diretamente com o correto funcionamento das ferramentas do MED. O usuário por sua vez, entrará em contato com esse sistema através das interfaces e suas interatividades.

Interface é a superfície de contato que reflete as propriedades físicas daqueles que interagem, como o exemplo da maçaneta que se comporta como a interface entre uma pessoa e a porta [24]. Relaciona-se à tradução, transformação e passagem, com o propósito de articular, transportar, conduzir. Uma vez bem projetada, ela servirá de apoio ao seu aprendizado, já que o usuário facilmente compreenderá a lógica do sistema, perceberá a localização e distinção das ferramentas disponibilizadas e os possíveis caminhos a percorrer, bem como as formas de comunicar-se através dela. Por outro lado, uma simples falha será responsável pelo seu desestímulo e conseqüente déficit no processo ensino-aprendizagem, podendo ainda resultar na rejeição do referido material.

Existem três pontos-chave na construção de uma interface [26]: “formato e densidade informacional”, relacionado à quantidade de informação que determinado usuário será capaz de traduzir baseado em suas limitações cognitivas ; “a localização desta informação na interface”, responsável pela escolha do melhor local para se localizar cada componente da interface; e "o modo de interação com o usuário”, relacionado a interação homem-máquina - referente aos feedbacks do sistema perante as ações do usuário e à fácil compreensão da lógica do sistema e humano-humano - proporcionando a sua comunicação com outros usuários. Outra forma de estruturação que vem sendo cada vez mais admirada pelos usuários e utilizada nos sites é a chamada Breadcrumbs (“Caminhos de Migalhas de Pão”). A navegação Breadcrumbs trata da representação textual de todo o conteúdo do site, normalmente escrito entre o sinal ">" e na parte superior da página web. Por exemplo: cinted>pósgraduação>monografia $>$, de modo a todos os textos serem links.

A atuação do design pedagógico está justamente em planejar essas questões técnicas de modo a elas apoiarem a trajetória autônoma e não-linear do usuário, possibilitando uma postura de livre-descoberta das interfaces e do conteúdo abordado. Para conquistar tal objetivo torna-se necessário que o planejamento do sistema seja baseado em interações - relação entre indivíduos [14] - e interatividades - relação entre o indivíduo e a máquina [18] Dessa forma, evita-se a utilização da tecnologia pela tecnologia, ou ainda a simples digitalização de materiais analógicos.

Segundo [7] os elementos de uma interação simples em interface são: Feedback de causa e efeito observável, em que o usuário consegue perceber que algo aconteceu; Coerência de efeito, de modo que a mesma ação acontece cada vez que o usuário repete o evento e Intuição razoável, em que o usuário consegue prever o que pode acontecer antes de iniciar um determinado evento.

Um fator importante que deve ser observado e auxilia no planejamento de uma boa interação e interatividade é o modelo conceitual. Segundo [22] modelo Conceitual é "uma descrição do sistema proposto - em termos de um conjunto de idéias e conceitos integrados a respeito do que ele deve fazer, de como deve se comportar e com o que deve se parecer - para que seja compreendida pelos usuários da maneira pretendida.” Segundo os referidos autores [22], trata-se do elemento mais importante a ser projetado do ponto de vista do usuário, sendo que todo restante está subordinado a tornar esse modelo claro, óbvio e substancial. O modelo conceitual adotado deve ser baseado nas necessidades do usuário. Além disso, é aconselhado que testes sejam realizados para verificar se o referido modelo conceitual utilizado será entendido pelo usuário da maneira pretendida. Um ponto importante nesse processo é essencialmente sobre o que os usuários farão para conseguir realizar os seus desafios. Se irão primeiramente pesquisar em páginas web, se irão navegar pelo material digital, experenciar simulações, comunicarse com colegas, entre outros.

Os modelos conceituais podem ser baseados em atividades ( Instrução - a base está na programação do sistema que premedita uma interatividade rápida e eficiente 
com o usuário; Conversação: - possibilita a interação entre colegas e professor; Manipulação e Navegação - a navegação é baseada em metáforas de objetos analógicos; Exploração e pesquisa: a exploração do MED ocorre através de uma navegação por livre-descoberta), baseados em objetos (interfaces remetem a objetos comuns de um certo cotidiano, ex.: adoção de uma metáfora de interface ou ícones de alto grau de iconicidade ) ou ainda mistos (Integração entre os modelos conceituais baseados em atividades e os baseados em objetos). Há também a opção de organizá-los na forma de metáforas de interface, baseadas em modelos conceituais que combinam conhecimento familiar a novos conceitos [22]. A vantagem é de o usuário entender melhor o sistema, compreendendo melhor o que faz e conquistando um maior controle de suas ações.

Outra prática seria a elaboração de modelos conceituais baseados em interatividades. Por exemplo, ao invés de navegar por um ambiente virtual com a metáfora de uma floresta para estudar a fauna e a flora brasileira, projetar uma cave ${ }^{1}$ onde o indivíduo poderia caminhar virtualmente pela floresta e até fotografar as plantas e animais através da sincronia entre diferentes tecnologias. Para isso alguns paradigmas de interação alternativos são propostos por pesquisadores [22]: - Computação Ubíqua (tecnologia inserida no ambiente de modo a ser utilizada sem ser notada) - Computação pervasiva (integração total de tecnologias, tornando possível o constante acesso e interação).

O tipo de interação e interatividade também pode variar de acordo com as características do sistema. No caso da adoção de um sistema fechado, as interatividades possibilitadas serão reativas. O usuário entrará em contato com uma programação fechada, ou seja, somente poderá optar por caminhos pré-estabelecidos pelo sistema, sendo impedido de criar trajetórias que não tenham sido pré-implementadas. Se uma situação não for pressuposta pela programação, ela não poderá produzir o mesmo resultado que a outra situação prevista apresentaria, podendo até não produzir qualquer resultado, ou gerar erros. Desse modo, o sistema reativo aproxima-se da relação estímulo-resposta. Quanto maior a combinação de variáveis previstas, maior será a aparência interpretativa do sistema.

Já a adoção de um sistema aberto propicia uma interatividade mútua, em que o usuário poderá modificar o sistema, pois seus elementos são interdependentes. No momento em que um deles é afetado, o sistema total se

\footnotetext{
${ }^{1}$ Cave - Caverna Digital. Nome originado da sigla inglesa Cave, que também forma a palavra caverna (Cave Automatic Virtual Enviroment). Fonte:
}

modifica. Esse fato possibilita que os resultados obtidos pelos usuários possam ser construídos de várias maneiras, independente da programação inicial do sistema. Ao contrário da relação estímulo-resposta, no sistema mútuo as interatividades ocorrem através da negociação. Enquanto o sistema reativo baseia-se no objetivismo, o mútuo baseia-se no relativismo. A adoção de um ou outro tipo de sistema dependerá da tecnologia disponível, do domínio da linguagem de programação do elaborador e do objetivo do material digital em questão.

Diante desses fatores técnicos, percebe-se que a interface é o elo de ligação entre o computador (programação) e o usuário e que vai bem mais além da simples organização de cores e ilustrações gráficas. A programação do sistema precisa auxiliar o usuário na tradução de significados e impulsionar sua exploração pelo material educacional digital. Por isso a importância do concomitante planejamento técnico-gráfico-pedagógico proposto pelo design pedagógico.

\section{Aplicação das metas do design peda- gógico na construção do objeto de a- prendizagem PEDESIGN}

Com o objetivo de avaliar as metas do design pedagógico e ao mesmo tempo gerar uma reflexão a respeito da aplicação do DP na elaboração de materiais educacionais digitais, este estudo construiu um objeto de aprendizagem chamado PEDESIGN (design pedagógico). Ele aplica as metas do design pedagógico ao mesmo tempo em que aborda como tema de estudo a construção de MED's sob o ponto de vista do design pedagógico. $\mathrm{O}$ objetivo foi validar (ou não) as metas do design pedagógico, assim como colaborar na formação de profissionais da área de educação, design e informática.

O objeto de aprendizagem foi desenvolvido em 4 etapas: concepção do projeto, planificação, construção do protótipo e avaliação, baseadas na metodologia de Amante e Morgado [2]. Sua elaboração baseia-se nas metas do design pedagógico.

O planejamento e execução foram realizados juntamente com a equipe do NUTED/UFRGS. Primeiramente foram definidos os objetivos pedagógicos, o conteúdo a ser abordado, os desafios, o storyboard e a temática de cada interface gráfica do objeto de aprendizagem. Após, foram realizadas reuniões com a equipe (composta por bolsistas da área de pedagogia, informática e design) de modo a discutir formas de execução e ir consolidando o projeto. Basicamente formaram-se dois grupos: Pedagógico - responsável pela elaboração do material teórico e planejamento das práticas pedagógicas a serem implementadas; Design - responsável pelo design das interfaces e pela programação em flash. 
O objeto de aprendizagem aborda questões a respeito da construção do design pedagógico, com o objetivo de propor uma reflexão a respeito da importância do design pedagógico na construção de materiais educacionais digitais. Possibilita a sua utilização em aulas presenciais ou virtuais (neste caso deverá ser apoiado por um ambiente virtual de aprendizagem). Encontra-se disponível no endereço http://www.nuted.edu.ufrgs.br/pedesign.

O OA propõe a contemplação de uma navegação predominantemente não-linear, possibilitando uma exploração com liberdade. Para tanto, o conteúdo encontra-se organizado na forma de hipertextos e hiperlinks, de modo a possibilitar que os materiais se intercomuniquem e o usuário possa investigar a teoria segundo a sua lógica. Aborda-se um caráter estésico através da adoção de metáforas de interface e da metodologia de "ação por descoberta” aplicada ao OA, possibilitando uma exploração instigante, investigativa e surpreendente. O planejamento gráfico da página inicial do PEDESIGN reporta à arte abstrata (figura 1), utilizando símbolos além dos tradicionais, evitando qualquer condicionamento de ordem de acesso. Objetiva-se que o aluno possa se sentir instigado a investigar o material educacional digital, valorizando a sua trajetória de aprendizagem e não apenas a obtenção de um resultado final. Para apoiar ainda mais esse fim, o conteúdo é organizado em forma de desafios de modo aos alunos terem a oportunidade de realizar experimentações e refletir sobre elas, utilizando para isso significados inteligíveis e sensíveis. São 8 desafios que abordam a aplicação dos principais elementos do design pedagógico. Eles podem ser realizados aleatoriamente (sem uma ordem específica), ou na seqüência que o professor escolher a partir da prática pedagógica aplicada. São eles: Contextualização da imagem em materiais educacionais digitais, A Utilização da Imagem, Teoria pura e experimentação, Navegação, Ruptura, Relacionando a ruptura e as simbologias trocadas, A Utilização da Imagem, Construção de um material educacional digital, Interação e Interatividade. Também são disponibilizados materiais de apoio, como: Biblioteca, Glossário, Guia e Bibliografia.

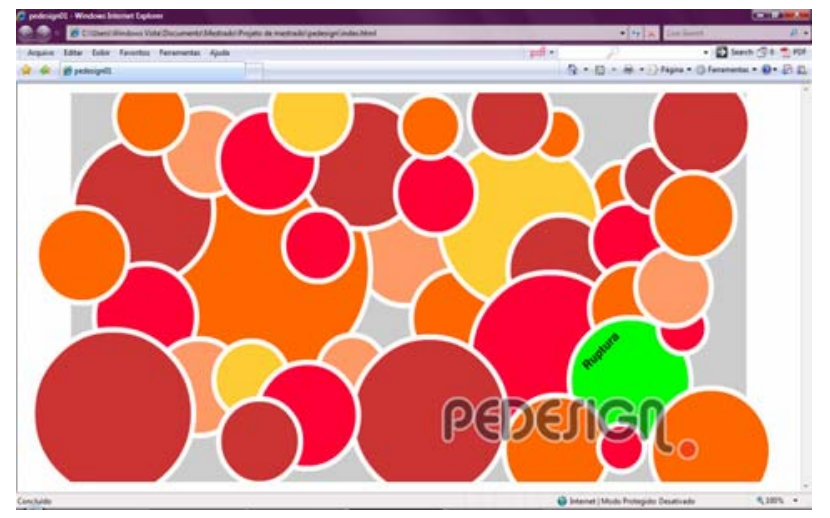

Figura 1: Tela inicial do OA PEDESIGN.

\section{Validação do Design Pedagógico}

A validação do conceito de Design Pedagógico ocorreu através da aplicação e avaliação do objeto de aprendizagem PEDESIGN, elaborado a partir das metas do Design Pedagógico. Esse processo é descrito na seção a seguir.

\subsection{Aplicação do OA PEDESIGN}

A Avaliação do objeto de aprendizagem PEDESIGN foi realizada através de um minicurso denominado PEDESIGN ministrado no $\mathrm{V}$ ESUD $/ 6^{\circ}$ SENAED, em abril de 2008, realizado em Gramado e na disciplina "Oficinas Virtuais de Aprendizagem” do curso de pós-graduação da Universidade Federal do Rio Grande do Sul (UFRGS), durante o primeiro semestre de 2008. A partir dessas práticas analisou-se tanto a relação aluno-objeto de aprendizagem, para verificar se a estrutura interativa aplicada no OA PEDESIGN contemplaria fatores ergonômicos e uma boa receptividade dentro de uma proposta diferenciada; quanto a relação aluno-objeto de estudo, com o objetivo de avaliar se a metodologia utilizada possibilitaria ou não a ação autônoma, investigativa e reflexiva do usuário sobre o conteúdo abordado.

No minicurso PEDESIGN participaram 15 profissionais da área da informática, entre eles: técnicos, programadores, professores e alunos de cursos voltados à informática. Os alunos, homens e mulheres, com idade entre 27 e 45 anos, tinham uma certa afinidade com as ferramentas informáticas, já que costumavam utilizar ferramentas informáticas no trabalho e em atividades diárias. A grande expectativa deles era aprender sobre a elaboração de interface de materiais educacionais digitais. Totalizando $6 \mathrm{~h} / \mathrm{a}$, o objetivo desta prática foi gerar uma reflexão a respeito dos principais fatores técnicos, gráficos e pedagógicos envolvidos durante a elaboração de MED's. Devido ao curto tempo de aplicação do referido OA neste minicurso, optou-se por avaliar apenas a relação aluno- objeto de aprendizagem.

Na oficina PEDESIGN, participaram 20 alunas. Elas tinham entre 27 e 50 anos, todas mulheres, algumas atuantes na área da educação e outras da informática. Nem todas tinham entrosamento com as ferramentas digitais. A expectativa dessas participantes era de estudar a elaboração de materiais educacionais digitais a partir do design pedagógico.O objetivo desta aplicação foi gerar a reflexão a respeito da importância do design pedagógico na construção de materiais educacionais digitais. $\mathrm{O}$ intuito foi possibilitar aos alunos experimentações através da sua livre navegação pelo $\mathrm{OA}$, de modo que eles pudessem, na prática, alcançar a ingenuidade suficiente para vivenciar o ponto de vista de futuros usuários e identificar os parâmetros envolvidos na construção de materiais educa- 
cionais digitais. Totalizando 20h/a, utilizou-se ainda, o ambiente virtual de aprendizagem (AVA) ROODA (Rede cooperativa de aprendizagem). Foram utilizadas as seguintes funcionalidades desse AVA: diário-de-bordo, Webfólio, Fórum de discussão, bate-papo e comunicador. O objetivo da utilização dessas funcionalidades foi analisar o processo de cada aluno e não apenas a produção final. Além disso, elas auxiliam no registro de dados, que por sua vez foram utilizadas na análise e discussão de dados da avaliação do OA PEDESIGN. O objetivo desta prática foi avaliar tanto a relação alunoobjeto de aprendizagem, como a relação aluno-objeto de estudo.

\section{Resultados - Tabela de Parâmetros para a construção de materiais educa- cionais digitais}

A partir da validação das metas do design Pedagógico e da necessidade verificada ao longo da realização deste estudo, elaborou-se uma tabela de parâmetros para a construção de materiais educacionais digitais sob o ponto de vista do design pedagógico. Ela foi elaborada a partir do cruzamento entre os dados coletados através do referencial teórico utilizado por esta pesquisa, das metas do design pedagógico e da aplicação do OA PEDESIGN. único fator não abordado por esta tabela é o referente à acessibilidade de usuários especiais, por exigir um estudo complexo que não conseguiria ser desenvolvido com qualidade no tempo de desenvolvimento deste trabalho. Pretende-se, na continuidade desta pesquisa e através da colaboração de outros grupos de pesquisa, adicioná-lo futuramente à esta tabela de parâmetros.

A tabela foi construída de modo a contemplar um caráter reutilizável, ou seja, de modo a permitir que cada equipe desenvolvedora adeque esses parâmetros-base às necessidades do seu usuário final. Portanto, ela não aborda "um modelo a ser seguido", ao contrário, salienta pontos importantes a serem levados em conta durante o planejamento e desenvolvimento de materiais educacionais digitais sob o ponto de vista do design pedagógico. Objetiva-se, desse modo, evitar basear a construção de MED’s num determinado padrão de usuário, mas possibilitar que todos padrões possam ser contemplados a partir da aplicação desta tabela de parâmetros, disposta a seguir.

\begin{tabular}{|c|c|c|c|}
\hline \multicolumn{4}{|c|}{ Parâmetros para a construção de materiais educacionais digitais baseados no design pedagógico } \\
\hline Parâmetros & & Metas do design pedagógico & \\
\hline Fatores Técnicos & Metas Técnicas & Metas Gráficas & Metas Pedagógicas \\
\hline Usabilidade & $\begin{array}{l}\text { Planejar o funcionamento do } \\
\text { sistema de modo a possibilitar que } \\
\text { o usuário facilmente construa uma } \\
\text { lógica de navegação pelo MED. } \\
\text { Fornecer retorno ao usuário de } \\
\text { modo a ele saber onde está, onde } \\
\text { esteve e onde poderá estar e de } \\
\text { que maneira. } \\
\text { Possibilitar que o sistema corres- } \\
\text { ponda às expectativas do usuário. } \\
\text { Possibilitar a resolução de uma } \\
\text { mesma tarefa através de vários } \\
\text { caminhos possíveis. } \\
\text { Elaborar estratégias de affordance } \\
\text { (fornecer pistas a respeito do } \\
\text { significado de um determinado } \\
\text { elemento de interface). } \\
\text { Controle Explícito - possibilitar ao } \\
\text { usuário o controle sobre suas } \\
\text { ações e uma eficaz comunicação } \\
\text { usuário-sistema. } \\
\text { Gestão de erros - projetar o siste- } \\
\text { ma de modo a ele ser capaz de } \\
\text { identificar, informar e consertar } \\
\text { possíveis erros. } \\
\text { Condução - ajudar o usuário no }\end{array}$ & $\begin{array}{l}\text { Utilizar fatores gráficos para } \\
\text { apoiar a interpretação do funcio- } \\
\text { namento do sistema pelo usuário e } \\
\text { para organizar as informações de } \\
\text { maneira legível, simples e eficien- } \\
\text { te. } \\
\text { Aplicar fatores gráficos que } \\
\text { revelem o conteúdo do site. } \\
\text { Visibilidade - estabelecer uma } \\
\text { relação lógica entre os ícones e a } \\
\text { função que desempenham. } \\
\text { Feedback - conciliar a expectativa } \\
\text { do usuário com a função dos } \\
\text { botões de navegação. } \\
\text { Mapeamento - relacionar a forma } \\
\text { dos ícones às suas funções. } \\
\text { Consistência - evitar a simples } \\
\text { digitalização do mundo real e de } \\
\text { materiais educacionais analógicos. } \\
\text { Carga de Trabalho - planejar uma } \\
\text { confortável carga de informação } \\
\text { em cada interface. } \\
\text { Adaptabilidade - contextualizar as } \\
\text { interfaces na cultura do usuário. }\end{array}$ & $\begin{array}{l}\text { Possibilitar controle e confian- } \\
\text { ça ao usuário, características } \\
\text { diretamente relacionadas com } \\
\text { a sua motivação e auto-estima. } \\
\text { Possibilitar apoio técnico para } \\
\text { que o aluno encontre liberdade } \\
\text { para zarpear pelo MED e criar } \\
\text { as suas estratégias de ação. } \\
\text { Caso haja alguma dificuldade } \\
\text { que o impeça de executar uma } \\
\text { das ações por ele planejada, } \\
\text { esse aluno perderá a confiança } \\
\text { no sistema e se desmotivará. } \\
\text { Desistirá de agir sobre o MED } \\
\text { de maneira autônoma e inves- } \\
\text { tigativa, se o sistema não o } \\
\text { apoiar. São os fatores ergonô- } \\
\text { micos que diferenciam um } \\
\text { desafio instigante de outro } \\
\text { desmotivador. Estão extrema- } \\
\text { mente relacionados com o } \\
\text { interesse, confiança e motiva- } \\
\text { ção do usuário. O aluno neces- } \\
\text { sita explorar o MED sem } \\
\text { reparar nas ferramentas, mas } \\
\text { na sua trajetória em si. }\end{array}$ \\
\hline
\end{tabular}




\begin{tabular}{|c|c|c|c|}
\hline & $\begin{array}{l}\text { decorrer de sua exploração pelo } \\
\text { material educacional digital. } \\
\text { Integrar os modelos conceituais } \\
\text { baseados em atividades aos basea- } \\
\text { dos em objetos. } \\
\text { Disponibilizar Breadcrumbs } \\
\text { (“Caminhos de Migalhas de Pão”) } \\
\text { e mapa do site. }\end{array}$ & $\begin{array}{l}\text { Consistência - contemplar uma } \\
\text { coerência entre as informações, } \\
\text { padronizações e a lógica dos } \\
\text { elementos das interfaces. } \\
\text { Compatibilidade - criar compo- } \\
\text { nentes nas interfaces responsáveis } \\
\text { pela interação homem-máquina e } \\
\text { que sejam compatíveis com o } \\
\text { estilo e personalidade do usuário. }\end{array}$ & \\
\hline Fatores Técnicos & Metas Técnicas & Metas Gráficas & Metas Pedagógicas \\
\hline Interação e interatividade & $\begin{array}{l}\text { Planejar a implementação de } \\
\text { ferramentas que possibilitem a } \\
\text { interatividade usuário-MED. } \\
\text { Planejar a implementação de } \\
\text { ferramentas que possibilitem a } \\
\text { interação entre usuários e entre } \\
\text { usuários e professores através do } \\
\text { MED ou planejar dinâmicas que } \\
\text { possibilitem uma ação interativa/ } \\
\text { colaborativa. } \\
\text { Fornecer feedbacks aos usuários } \\
\text { (jogos educacionais e mensagens } \\
\text { do sistema). } \\
\text { Adotar uma navegação não-linear. } \\
\text { Estruturar o MED a partir da } \\
\text { adoção de modelos conceituais } \\
\text { (preferencialmente o misto). }\end{array}$ & $\begin{array}{l}\text { Utilizar fatores gráficos que } \\
\text { apóiem as ações e necessidades do } \\
\text { usuário ao se comunicar com } \\
\text { outros usuários ou com o sistema. } \\
\text { Expressividade - estabelecer uma } \\
\text { relação entre os símbolos utiliza- } \\
\text { dos e o seu significado. }\end{array}$ & $\begin{array}{l}\text { Apoiar a trajetória do usuário } \\
\text { pelo MED. } \\
\text { Planejar "materiais de apoio": } \\
\text { biblioteca, guia do professor, } \\
\text { glossário, entre outros. } \\
\text { Possibilitar a ação do usuário } \\
\text { sobre o MED. } \\
\text { Permitir que o usuário interaja } \\
\text { com vários tipos de informa- } \\
\text { ção, instigando uma relação } \\
\text { com os seus conceitos pré- } \\
\text { estabelecidos. } \\
\text { Oportunizar a interação com } \\
\text { outros usuários e professores, } \\
\text { contemplando o desenvolvi- } \\
\text { mento de habilidades sociais e } \\
\text { colaborativas. } \\
\text { Organizar o conteúdo de modo } \\
\text { a desafiar o usuário a desco- } \\
\text { bertas. } \\
\text { Possibilitar a navegação por } \\
\text { livre-descoberta. } \\
\text { Fazer prevalecer a interação } \\
\text { mútua à reativa. }\end{array}$ \\
\hline Fatores Gráficos & Metas Técnicas & Metas Gráficas & Metas Pedagógicas \\
\hline Design & $\begin{array}{l}\text { Os ícones devem seguir uma } \\
\text { lógica facilmente entendível pelo } \\
\text { usuário. } \\
\text { Alternar o grau de iconicidade } \\
\text { (baixo/médio/alto), conforme a } \\
\text { necessidade. } \\
\text { Design comportamental: planejar } \\
\text { o uso e a relação entre os elemen- } \\
\text { tos da interface. } \\
\text { Observar os hábitos do usuário } \\
\text { final. } \\
\text { Avaliar o MED através da prototi- } \\
\text { pação. } \\
\text { Admitir o usuário na equipe } \\
\text { desenvolvedora do MED. } \\
\text { Constante avaliação da aplicação } \\
\text { do design no MED. } \\
\text { Design centrado na ação do usuá- } \\
\text { rio [19]: uso de coerções, tornar as } \\
\text { “coisas” visíveis, fácil avaliação } \\
\text { do estado do sistema, mapeamen- }\end{array}$ & $\begin{array}{l}\text { Os elementos de composição } \\
\text { devem estar contextualizados no } \\
\text { perfil do público-alvo e no conte- } \\
\text { údo abordado pelo MED. } \\
\text { Design reflexivo: possibilitar que } \\
\text { o usuário identifique-se com o } \\
\text { MED. } \\
\text { Design visceral: voltá-lo ao envol- } \\
\text { vimento do usuário. } \\
\text { Ater-se ao formato e densidade } \\
\text { informacional das interfaces e } \\
\text { localização das informações. } \\
\text { Utilizar simbologias-padrão } \\
\text { alternadas à sua ruptura. } \\
\text { Fazer uso de metáforas, sempre } \\
\text { que pertinente. } \\
\text { Utilizar imagens estáticas, } \\
\text { dinâmicas e animações interativas. } \\
\text { Aplicar o princípios uniformizado- } \\
\text { res para a comunicação didática e } \\
\text { o design: Regularidade, uniformi- }\end{array}$ & $\begin{array}{l}\text { Os elementos de composição } \\
\text { devem ser considerados parte } \\
\text { integrante do MED e não } \\
\text { meros elementos decorativos. } \\
\text { As imagens, animações e } \\
\text { simulações devem fornecer } \\
\text { resistência à ação do usuário, } \\
\text { para que ele possa interagir } \\
\text { com conceitos prévios e } \\
\text { novos. } \\
\text { Possibilitar que o usuário } \\
\text { identifique-se com o MED. } \\
\text { Motivação e instigação do } \\
\text { usuário: trabalhar com a } \\
\text { ruptura da simbologia padrão e } \\
\text { a contextualização das interfa- } \\
\text { ces na cultura do usuário e no } \\
\text { conteúdo abordado. } \\
\text { Administrar a aplicação do } \\
\text { caráter lúdico de metáforas e } \\
\text { simulações, com o objetivo do } \\
\text { aluno desprender-se da tensão } \\
\text { de aprender e valorizar a sua }\end{array}$ \\
\hline
\end{tabular}




\begin{tabular}{|c|c|c|c|}
\hline & $\begin{array}{l}\text { tos, simplificar a estrutura das } \\
\text { tarefas, adotar auxiliares mneumô- } \\
\text { nicos, projetar para o erro. } \\
\text { O sistema deve ser projetado para } \\
\text { apoiar o comportamento do usuá- } \\
\text { rio e o contexto. } \\
\text { Design participativo: possibilitar a } \\
\text { participação ativa do usuário no } \\
\text { sistema operacional. } \\
\text { Projetar uma relação harmônica } \\
\text { entre o mapa conceitual do siste- } \\
\text { ma, usuário e designer. } \\
\text { Utilizar ícones que se relacionem } \\
\text { com os signos do usuário e com a } \\
\text { composição gráfica da interface, } \\
\text { de modo a contemplar o conceito } \\
\text { de relevância. }\end{array}$ & $\begin{array}{l}\text { dade de elementos baseada num } \\
\text { mesmo princípio ou plano; Predic- } \\
\text { tibilidade, similaridade entre } \\
\text { elementos de mesma função; } \\
\text { Economia, concisão de elementos } \\
\text { para estruturar a mensagem de um } \\
\text { modo mais simples possível; } \\
\text { Sequenciação, plano de apresenta- } \\
\text { ção para orientação da interpreta- } \\
\text { ção; Unidade,coerência da totali- } \\
\text { dade dos elementos que estão } \\
\text { todos em uma peça; Simplicidade, } \\
\text { orientação e unidade de tratamento } \\
\text { da forma; Agrupamento, estabele- } \\
\text { cer estrutura e forma significativa. } \\
\text { Aplicar as “mensagens do desig- } \\
\text { ner" elaboradas pela LEMD. }\end{array}$ & $\begin{array}{l}\text { trajetória de aprendizagem. } \\
\text { Ultrapassar os limites da } \\
\text { simples contemplação e repre- } \\
\text { sentação, de modo ao observa- } \\
\text { dor atuar de maneira crítica } \\
\text { sobre o MED. } \\
\text { Apoiar a comunicação } \\
\text { didática. }\end{array}$ \\
\hline Fatores Gráficos & \multicolumn{2}{|l|}{ Metas Técnicas } & Metas Pedagógicas \\
\hline Estética & $\begin{array}{l}\text { Planejar uma estética participativa: } \\
\text { diálogo entre o usuário e o MED. } \\
\text { Aplicar e relacionar as cinco } \\
\text { estéticas de Greimas [10]: estética } \\
\text { clássica, estética da graça, estética } \\
\text { da revelação, estética da penetra- } \\
\text { ção e estética da purificação. } \\
\text { Criar experiências estéticas apoi- } \\
\text { ando-se em fatores ergonômicos e } \\
\text { nas tecnologias digitais. }\end{array}$ & $\begin{array}{l}\text { Aplicar a media art e a endoestéti- } \\
\text { ca. } \\
\text { Utilizar a arte como fator sensibi- } \\
\text { lizador. } \\
\text { Não vincular a estética apenas ao } \\
\text { belo, mas, acima de tudo, à expe- } \\
\text { riência estética. }\end{array}$ & $\begin{array}{l}\text { Possibilitar situações de } \\
\text { aprendizagem através da } \\
\text { estética participativa e da } \\
\text { experiência estética. } \\
\text { Propiciar que o usuário inter- } \\
\text { prete criticamente o conteúdo } \\
\text { em estudo (diálogo entre MED } \\
\text { e usuário). } \\
\text { Possibilitar que o aluno parti- } \\
\text { cipe ativamente no processo } \\
\text { de construção do conhecimen- } \\
\text { to ao contrário de apenas } \\
\text { assistir a distância o desenrolar } \\
\text { de um conteúdo (aprender ao } \\
\text { invés de simplesmente conhe- } \\
\text { cer). } \\
\text { Utilizar a tecnologia digital } \\
\text { para implementar experiências } \\
\text { estéticas e apoiar as situações } \\
\text { de aprendizagem planejadas } \\
\text { pela equipe pedagógica. }\end{array}$ \\
\hline Semiótica & $\begin{array}{l}\text { Aplicar a semiótica peirceana no } \\
\text { planejamento de ícones relaciona- } \\
\text { dos a navegação e usabilidade. } \\
\text { Aplicar a relação plano de conteú- } \\
\text { do x plano de expressão, da semió- } \\
\text { tica greimasiana, na organização } \\
\text { do conteúdo abordado pelo MED. } \\
\text { Relação de ajuda - propiciar um } \\
\text { diálogo entre o sistema e o usuário } \\
\text { de modo ao aluno sentir-se insti- } \\
\text { gado pelos desafios e não desesti- } \\
\text { mulado. }\end{array}$ & $\begin{array}{l}\text { Sensibilizar o usuário a partir do } \\
\text { planejamento estético das interfa- } \\
\text { ces. } \\
\text { Relativização do discurso - possi- } \\
\text { bilitar que o usuário atue critica- } \\
\text { mente sobre o conteúdo (constru- } \\
\text { ção de efeitos de sentido para o } \\
\text { objeto de estudo). } \\
\text { Relacionar os diversos tipos de } \\
\text { linguagem aplicada no MED. }\end{array}$ & $\begin{array}{l}\text { Romper a dessemantizada } \\
\text { rotina cotidiana, possibilitando } \\
\text { que o usuário crie efeitos de } \\
\text { sentido para o conteúdo estu- } \\
\text { dado. } \\
\text { Organizar o conteúdo de modo } \\
\text { a possibilitar que o usuário, ao } \\
\text { interagir com esse conteúdo, } \\
\text { elabore uma rede de relações: } \\
\text { contrariedade, contraditorie- } \\
\text { dade, implicações. } \\
\text { Possibilitar que o aluno, } \\
\text { através da construção de } \\
\text { efeitos de sentido para o } \\
\text { conteúdo, sinta-se motivado a } \\
\text { aprender. } \\
\text { Instigar o aluno a partir do } \\
\text { caráter estésico. } \\
\text { Relacionar os saberes sensível } \\
\text { e inteligível. }\end{array}$ \\
\hline
\end{tabular}

Tabela 1: Parâmetros para a construção de materiais educacionais digitais baseados no design pedagógico. 


\section{Considerações Finais}

Através deste estudo, verifica-se que a aprendizagem significativa é construída quando o paradigma da aprendizagem mecânica e meramente observável é ultrapassado. Na atual sociedade, o acesso à informação encontra-se facilitado pelas tecnologias digitais, principalmente através das redes de informação. Porém, o diferencial estará em como aplicá-las e não apenas em descobri-las. Para isso, o pensamento crítico tornase fundamental. Sem ele não há criação e, segundo Piaget [14], o conhecimento é o constante ato de criar. Por essa razão o design pedagógico propõe a integração de fatores técnicos, gráficos e pedagógicos, de modo a possibilitar ao usuário uma ação autônoma e investigativa. Verifica-se que a simples comunicação de um conceito não é suficiente para a construção de uma aprendizagem significativa. O usuário necessita situarse diante dessa informação, integrá-la aos seus conhecimentos prévios e aplicá-la na criação de novidades.

O planejamento gráfico e interativo das interfaces, por sua vez, possui um papel importante na contemplação desse objetivo pedagógico. O usuário de um mate-

\section{Referências}

[1] G. T. V. Affonso. A Complexidade Da Imagem No Processo Educacional. Disponível em: <http://helamor.multiply.com/journal/item/89> . Acesso em: 12/07/2007.

[2] L. Amante,; L. Morgado. Metodologia de concepção e desenvolvimento de aplicações educativas: o caso dos materiais hipermedia. In: Discursos, III Série, $\mathrm{n}^{0}$ especial, pp.125138, Universidade Aberta, 2001.

[3] Sérgio B. Amaral; Gilda H. B.Campos; Gianna O. Roque. Dialética da educação a distância. Ed. PUC-Rio, Rio de Janeiro, 2007.

[4] M. P. Baron; S. I. Dorocinski; N. T. Lubi Finck; M. L. Kriegl; A. Pelizzari. TEORIA DA APRENDIZAGEM SIGNIFICATIVA SEGUNDO AUSUBEL. Disponível em: $<$ http://vicenterisi.googlepages.com/teoria_da_ aprendizagem_Ausubel.pdf $>$. Acesso em: 20/01/2008.

[5] F. Becker. Seminário Limites e possibilidades lógicas da criança e do adolescente. Programa de Pós-Graduação da Faculdade de Educação da Universidade Federal do Rio Grande do Sul. Porto Alegre, $2^{\circ}$ semestre 2007.

[6] M. Bense. (1986). Repräsentation und Fundierung der Realitäten: Fazit semiotischer rial educacional digital utilizará a interface para percorrer o seu conteúdo e realizar as suas atividades. Portanto, uma vez bem projetada, ela servirá de apoio ao seu aprendizado, já que o usuário facilmente compreenderá a lógica do sistema, perceberá a localização e distinção das ferramentas disponibilizadas e os possíveis caminhos a percorrer, bem como as formas de comunicar-se através dela. Por outro lado, uma simples falha será responsável pelo seu desestímulo e conseqüente déficit no processo de ensinoaprendizagem, podendo ainda resultar na rejeição do referido material. É preciso projetar a interface ao mesmo tempo em que se planeja o conteúdo a ser abordado, a metodologia pedagógica a ser aplicada e a programação computacional. Logo, dentro deste contexto, este estudo elaborou as metas do design pedagógico e, após validá-las, as aplicou na construção da tabela de parâmetros para a construção de materiais educacionais digitais baseados no design pedagógico. O intuito é colaborar com a formação de profissionais da área da educação, design e informática, bem como também com a construção de materiais educacionais digitais que possibilitem a ação crítica do aluno sobre o MED.

Perspektiven. Baden-Baden: Agis. BENSE, Max \% Elisabeth WALTHER, orgs. (1973). Wörterbuch der Semiotik. Köln: Kiepenheuer \& Witsch.

[7] Stephan V. Bugaj. Projetando Espaços 3-D para WEB. Cap.11, p. 340 a

391. publicado no livro Interatividade na web : transforme seu site em uma experiência inesquecível. São Paulo : Berkeley, 1997. 494 p.

[8] E. Canetti. Uma luz em meu ouvido: História de uma vida. 1921-1931. Trad. de Kurt Jahn. São Paulo: Cia. das Letras, 1989.

[9] C. S. DE Souza, (1993). The semiotic engineering of user interface languages. Int. J. Man-Mach. Stud., 39(5):753-773. 
[10] J. Ferreira. 2005. Semiotic Explorations in User Interface Design. Disponível em: $<$ http://www.mcs.vuw.ac.nz/comp/graduates/a rchives/honours/2004/jennifer-ferreira-finalreport.pdf> Acesso em: 02/02/2009.

[11] Alex S. Gomes. Referencial teórico construtivista para avaliação de software educativo. In: RBIE - Revista Brasileira de Informática na Educação. Volume 16 - Número 2 - Maio a Agosto de 2008. Disponível em: <http://bibliotecadigital.sbc.org.br/>. Acesso em: 30/11/2009.

[12] A. J. Greimas; Courtés. Dicionário de Semiótica. Trad. De Alceu Dias Lima e outros. São Paulo, Cultrix, 1989.

[13] A. J. Greimas. Da Imperfeição. São Paulo: Hacker Editores, 2002.

[14] J. Piaget ; P. Greco. Aprendizagem e conhecimento. São Paulo: Freitas Bastos (1974).

[15] J. Piaget. Epistemologia genética. São Paulo: Martins Fontes, 1990.

[16] J. F. D. Junior. O SENTIDO DOS SENTIDOS:A EDUCAÇÃO (DO) SENSÍVEL. Orientador: Moraes, João F. R. Universidade Federal de Campinas, Faculdade de Educação, 2000. Biblioteca Digital da UNICAMP. Disponível em: $<$ http://libdigi.unicamp.br/document/?code=vtls00 0211363>. Acesso em: 20/01/2008.

[17] J. C. Leite, (1998). Modelos e Formalismos para Engenharia Semiótica de Interfaces de Usuário. Tese de Doutorado, Departamento e Informática, PUC-Rio.

[18] D. L. Lemos, Apostila de Informática Básica. 2008. Disponível em:

$<$ http://www.cefetsc.edu.br/ geomensura/>.Acesso em: 20/02/09.

[19] D. A. Norman. O Design Do Dia-A-Dia. Rio de Janeiro: Ed. ROCCO, 2006.

[20] L. Paas. Design educacional. UFSC, LIED, 2001. Disponível em:

<http://www.eps.ufsc.br/disc/tecmc/designedu.html>. Acesso em: 12/2001.

[21] R. M. Palloff; K. Pratt. O Aluno Virtual: um guia para trabalhar com estudantes on-line. Trad. FIGUEIRA, Vinícius. Ed. Artmed, Porto Alegre, 2004.

J. Preece et al. Design de Interação: além da interação homem-computador. Porto Alegre: Book- man, 2005.

S. R. Ramalho e Oliveira. Imagem também se lê. São Paulo: Edições Rosari, 2005.

H. Rocha et al. Ambientes para a educação a

[24] distância baseados na web: Onde estão as pessoas? Artigo publicado nos anais do III Workshop sobre Fatores Humanos em Sistemas e Computação. Gramado, RS, 2000.

A. Romiszowski; L. Romiszowski. Retrospectiva e Perspectivas do Design Instrucional e Educação a Distância: análise da literatura. Revista Brasileira de Aprendizagem Aberta e a Distância. v. 3, n. 1, 2005. Disponível em:

$<$ http://www.abed.org.br $>$. Acesso em: 15/01/2008.

[26] R. Rosa. A importância do projetista de interfaces. Disponível em:

$<$ http://webinsider.uol.com.br/index.php/2005/06/ 06/a-importancia-doprojetista- de-interfaces/> Acesso em 20/11/06.

[27] L. Santaella; W. Nöth. Imagem: Cognição, semiótica, mídia. São Paulo, Iluminuras, 1998.

[28]

J. R. C. Silveira. A imagem: interpretação e comunicação. Revista Linguagem em (Dis)curso, volume 5, número especial, 2005. Disponível em: $<$ http://www3.unisul.br/paginas/ensino/pos/lingua gem/0503/05.htm> Acesso em: 20/07/2007.

[29] Wallace Ugulino; Ricardo R. Nunes; Mariano Pimentel. Em busca de melhores MODUS de realizar dinâmicas educacionais colaborativas. In: XV WIE - Workshop Sobre Educação na Escola. Jul 2009. Bento Gonçalves - RS. Disponível em: $<$ http://bibliotecadigital.sbc.org.br/> . Acesso em: 30/11/2009. 